\title{
Protein restriction in early life is associated with changes in insulin sensitivity and pancreatic $\boldsymbol{\beta}$-cell function during pregnancy
}

\author{
Letícia Martins Ignácio-Souza ${ }^{1}$, Sílvia Regina Reis ${ }^{2}$, Vanessa Cristina Arantes ${ }^{3}$, Bárbara Laet Botosso ${ }^{2}$, \\ Roberto Vilela Veloso ${ }^{3}$, Fabiano Ferreira ${ }^{4}$, Antonio Carlos Boschero ${ }^{5}$, Everardo Magalhães Carneiro ${ }^{5}$, \\ Marise Auxiliadora de Barros Reis ${ }^{3}$ and Márcia Queiroz Latorraca ${ }^{3 *}$ \\ ${ }^{1}$ Mestrado em Biociências, Faculdade de Nutrição, Universidade Federal de Mato Grosso, \\ Avenida Fernando Correa da Costa, 2367, Boa Esperança, 78060-900 Cuiaba, MT, Brazil \\ ${ }^{2}$ Laboratório de Avaliação Biológica de Alimentos, Faculdade de Nutrição, Universidade Federal de Mato Grosso, \\ Avenida Fernando Correa da Costa, 2367, Boa Esperança, 78060-900 Cuiaba, MT, Brazil \\ ${ }^{3}$ Departamento de Alimentos e Nutrição, Faculdade de Nutrição, Universidade Federal de Mato Grosso, \\ Avenida Fernando Correa da Costa, 2367, Boa Esperança, 78060-900 Cuiaba, MT, Brazil \\ ${ }^{4}$ Departamento de Fisiologia e Farmacologia da Universidade Federal de Pernambuco, Avenida Professor Moraes Rego, \\ 1235, Cidade Universitária, 50670-901 Recife, PE, Brazil \\ ${ }^{5}$ Departamento de Anatomia, Biologia Celular e Fisiologia, Instituto de Biologia, Universidade Estadual de Campinas, \\ Avenida Bertrand Russel, s/n, Cidade Universitária Zeferino Vaz, 13083-865 Campinas, SP, Brazil
}

(Submitted 11 July 2011 - Final revision received 3 February 2012 - Accepted 6 February 2012 - First published online 5 April 2012)

\begin{abstract}
Malnutrition in early life impairs glucose-stimulated insulin secretion in adulthood. Conversely, pregnancy is associated with a significant increase in glucose-stimulated insulin secretion under conditions of normoglycaemia. A failure in $\beta$-cell adaptive changes may contribute to the onset of diabetes. Thus, glucose homeostasis and $\beta$-cell function were evaluated in control-fed pregnant (CP) and non-pregnant (CNP) or protein-restricted pregnant (LPP) and non-pregnant (LPNP) rats, from fetal to adult life, and in protein-restricted rats that were recovered after weaning (RP and RNP). The typical insulin resistance of pregnancy was not observed in the RP rats, nor did pregnancy increase the insulin content/islet in the LPP group. The glucose dose-response curves from pregnant rats were shifted to the left in relation to the nonpregnant rats, except in the recovered group. Glucose utilisation but not oxidation in islets from the RP and LPP groups was reduced at a concentration of $8.3 \mathrm{~mm}$-glucose compared with islets from the CP group. Cyclic AMP content and the potentiation of glucose-stimulated insulin secretion by isobutylmethylxanthine at a concentration of $2.8 \mathrm{~mm}$-glucose indicated increased adenylyl cyclase 3 activity but reduced protein kinase A- $\alpha$ activity in islets from the RP and LPP rats. Protein kinase C (PKC)- $\alpha$ but not phospholipase C (PLC)- $\beta 1$ expression was reduced in islets from the RP group. Phorbol-12-myristate 13-acetate produced a less potent stimulation of glucose-stimulated insulin secretion in the RP group. Thus, the alterations exhibited by islets from the LPP group appeared to be due to reduced islet mass and/or insulin biosynthesis. In the RP group the loss of the adaptive capacity apparently resulted from uncoupling between glucose metabolism and the amplifying signals of the secretory process, as well as a severe attenuation of the PLC/PKC pathway.
\end{abstract}

Key words: Glucose homeostasis: Insulin secretion: Malnutrition: Nutritional recovery: Pregnancy

The basic mechanism of insulin secretion involves the coupling of glucose metabolism with secondary signals, which maintains insulin release for the duration of elevated blood glucose levels $^{(1)}$

In rodents, malnutrition during the critical stages of development causes a permanent loss of glucose sensitivity and secretory capacity in pancreatic islets ${ }^{(2)}$, which is probably the result of alterations to the coupling of stimuli with insulin secretion. In pancreatic islets from rats fed a low-protein (LP) diet during intra-uterine life and/or lactation, reductions in glucokinase (Gck) and hexokinase (Hxk) activity and content ${ }^{(3)}$, decreases in $\mathrm{Ca}^{2+}$ uptake and/or $\mathrm{Ca}^{2+}$ efflux ${ }^{(4)}$, and impairments in insulin

Abbreviations: $\Delta G$, total area under the glucose curve; $\Delta \mathrm{I}$, total area under the insulin curve; AC3, adenylyl cyclase 3; C, control; cAMP, cyclic AMP; CNP, control non-pregnant; CP, control pregnant; Gck, glucokinase; GLUT2, glucose transporter 2; Hxk, hexokinase; IBMX, isobutylmethylxanthine; $\mathrm{K}_{\text {itt }}$, constant rate for plasma glucose disappearance; LP, low protein; LPNP, low-protein non-pregnant; LPP, low-protein pregnant; PKA, protein kinase A; PKC, protein kinase C; PLC, phospholipase C; PMA, phorbol-2-myristate 13-acetate; R, recovered; RNP, recovered non-pregnant; RP, recovered pregnant.

*Corresponding author: M. Q. Latorraca, fax +55 653615 8811, email mqlator@terra.com.br 
secretion in response to activators of the cyclic AMP (cAMP)/protein kinase A (PKA) and phospholipase C (PLC)/protein kinase $\mathrm{C}$ (PKC) pathways ${ }^{(5)}$ have been observed.

During pregnancy, several reversible $\beta$-cell adaptations occur to compensate for the increased demand for insulin, and these adaptations include enhanced secretion and a lower threshold for glucose-stimulated insulin secretion ${ }^{(6-8)}$. Adaptations to insulin secretion and stimulation thresholds are mediated, at least in part, by changes in the activity/content of key enzymes involved in glucose metabolism (glucose transporter 2 (GLUT2), Gck and Hxk) as well as by modulation of the insulin secretory process (PLC/PKC and CAMP/PKA) ${ }^{(9-11)}$.

Permanent damage to the secretory process, resulting from early protein restriction, may impair classical $\beta$-cell adaptation during pregnancy and contribute to the onset of diabetes. Thus, in the present study, we evaluated glucose homeostasis and investigated various steps involved in the coupling of stimuli with insulin secretion, particularly those that may be involved in impaired $\beta$-cell sensitivity to glucose and a reduced activation threshold for glucose-stimulated insulin secretion. The present study examined islets isolated from pregnant or non-pregnant rats that had been exposed to a low-protein (LPP and LPNP, respectively) or control (CP and CNP, respectively) diet from the fetal stage until adulthood, as well as islets isolated from pregnant and non-pregnant rats that had been protein-restricted during intra-uterine life and lactation but were then allowed to recover after weaning (RP and RNP, respectively).

\section{Materials and methods}

\section{Animals and diets}

The experimental procedures involving rats were performed in accordance with the guidelines of the Brazilian College for Animal Experimentation (COBEA) and were approved by the Ethics Committee at the Federal University of Mato Grosso (protocol no. 23108.002104/08-5). Male and virgin female Wistar rats (85-90 d old) were obtained from the University's own breeding colony. Pairing was performed by housing males with females overnight (one male with four females), and pregnancy was confirmed by the examination of vaginal smears for the presence of sperm. Pregnant females were separated at random and maintained from the first day of pregnancy until the end of lactation on isoenergetic diets containing either $6 \%$ protein (LP diet) or 17\% protein (control (C) diet). Spontaneous delivery took place at day 22 of pregnancy, and large litters were then reduced to eight pups when they were $3 \mathrm{~d}$ of age to ensure a standard litter size per mother. At weaning (fourth week after birth), females were divided into three groups: C, consisting of offspring born to and suckled by mothers fed a $\mathrm{C}$ diet and subsequently fed the same diet after weaning; LP, consisting of the offspring of mothers fed a LP diet and subsequently fed the same diet after weaning; R, consisting of the offspring of mothers fed a LP diet, but fed a C diet after weaning. At $90 \mathrm{~d}$ old, pairing was performed and the CNP and CP groups and the RNP and RP groups were fed a $\mathrm{C}$ diet, whereas the LPNP and LPP groups were maintained on a LP diet from the first day until the 19th day or from first day until the 15th day of pregnancy. The diets were isoenergetic, as described by Milanski et $a l .{ }^{(12)}$. During the experimental period, the rats had access to their respective diets and to water ad libitum and were housed at $22^{\circ} \mathrm{C}$ with a $12 \mathrm{~h}$ light $-12 \mathrm{~h}$ dark cycle. In vivo studies have shown that pregnant rats become progressively resistant to insulin after day 16 of pregnancy ${ }^{(13)}$. On the other hand, it has been observed that in isolated perfused pancreases, the glucose stimulation threshold reached a nadir of 3.25 mm-glucose on days 12 and 15 of pregnancy, and insulin secretion peaked at 4 -fold on day 15 of pregnancy ${ }^{(8)}$. Thus, one group of rats was maintained on the dietary regimen until day 15 of pregnancy, when the islets were isolated to evaluate insulin secretion. The second group of rats was maintained on the study diet until $19 \mathrm{~d}$ of pregnancy, during which the glucose and insulin tolerance tests were performed to evaluate insulin sensitivity. After undergoing the insulin tolerance test, rats were anaesthetised with sodium thiopental and decapitated, and the body weights of fetuses were recorded. The remaining rats were weighed and euthanised, and blood was collected for biochemical analysis. Since it was not possible to evaluate all variables in the same animal, the number of individual experiments varied among the groups, but was representative of at least three different litters.

\section{Glucose tolerance test}

After a $12 \mathrm{~h}$ fast, glucose (200 g/l) was administered intraperitoneally at a dose of $2 \mathrm{~g} / \mathrm{kg}$ body weight. Blood samples were obtained from the cut tip of the tail at 0, 30, 60 and $120 \mathrm{~min}$ post-injection for the determination of serum glucose and insulin concentrations. The trapezoidal method was used to calculate glucose and insulin responses during the glucose tolerance test. These responses were calculated by estimating the total area under the glucose $(\Delta G)$ and insulin $(\Delta \mathrm{I})$ curves $^{(14)}$.

\section{Insulin tolerance test}

After a $12 \mathrm{~h}$ fast, insulin (regular) was administered intraperitoneally at a dose of $1.5 \mathrm{U} / \mathrm{kg}$ body weight. Blood samples were obtained from the cut tip of the tail at 0, 5, 10 and $15 \mathrm{~min}$ post-injection for the determination of serum glucose concentrations. The glucose response during the insulin tolerance test was evaluated by the constant of disappearance of plasma glucose $\left(\mathrm{K}_{\mathrm{itt}}\right)$ that was calculated from the slope of the fall in log-transformed plasma glucose between 0 and $15 \mathrm{~min}$ after insulin administration ${ }^{(15)}$, when the glucose concentration declined linearly.

\section{Serum parameters}

Blood samples were collected and allowed to clot. Sera were stored at $-20^{\circ} \mathrm{C}$ for the subsequent measurement of serum glucose by the oxidase-peroxidase method ${ }^{(16)}$, and serum albumin concentrations were determined by a colorimetric $\operatorname{method}^{(17)}$. Serum insulin levels were determined by RIA ${ }^{(18)}$. 


\section{Total insulin content and insulin secretion in isolated islets}

Islets were isolated by collagenase digestion of the pancreas, as described by Boschero et $a l^{(19)}$. For each experimental group, twenty islets were sonicated in $1 \mathrm{ml}$ of distilled water and maintained at $-20^{\circ} \mathrm{C}$ until total insulin content determination by RIA ${ }^{(18)}$.

Groups of five islets were first incubated for $45 \mathrm{~min}$ at $37^{\circ} \mathrm{C}$ in Krebs-bicarbonate buffer with the following composition: $115 \mathrm{~mm}-\mathrm{NaCl}, 5 \mathrm{~mm}-\mathrm{KCl}, 2.56 \mathrm{~mm}-\mathrm{CaCl}_{2}, 1 \mathrm{~mm}-\mathrm{MgCl}_{2}, 10 \mathrm{~mm}-$ $\mathrm{NaHCO}_{3}, 15 \mathrm{~mm}-\mathrm{HEPES}$ and $5.6 \mathrm{~mm}$-glucose, supplemented with $3 \mathrm{~g}$ bovine serum albumin/l and equilibrated with a mixture of $95 \% \mathrm{O}_{2}-5 \% \mathrm{CO}_{2}$ to give a $\mathrm{pH}$ of $7 \cdot 4$. This medium was replaced with fresh buffer, and then the islets were further incubated for $1 \cdot 5 \mathrm{~h}$ with glucose concentrations of $2 \cdot 8,5 \cdot 6,8 \cdot 3$, 11.1 and $16.7 \mathrm{~mm}$. The glucose concentration producing a response that was $50 \%$ of the maximum ( $50 \%$ effective concentration) was expressed as the mean negative logarithm $\left(\mathrm{pD}_{2}\right)$.

In the second series of the experiments, insulin secretion was measured in response to the following: (1) glucose (2.8 or $8.3 \mathrm{~mm})$ in the absence and presence of isobutylmethylxanthine (IBMX $1 \mathrm{~mm}$; Sigma) and (2) glucose $(2.8$ or $8.3 \mathrm{~mm})$ in the absence or presence of phorbol-12-myristate 13-acetate (PMA; $100 \mathrm{~nm}$; Sigma). The insulin released was measured by RIA using rat insulin as the standard ${ }^{(18)}$.

\section{Glucose metabolism}

The rate of glucose metabolism was measured in islets freshly isolated by collagenase digestion.

\section{2-Deoxy-D-glucose uptake}

Groups of twenty islets were incubated in $100 \mu \mathrm{l}$ of buffered Krebs-bicarbonate solution supplemented with $3 \mu \mathrm{Ci}$ $\left[{ }^{14} \mathrm{C}\right] 2$-deoxy-D-glucose (Amersham Biosciences) with enough unlabelled glucose (Sigma-Aldrich) to achieve a final concentration of 2.8 or $8.3 \mathrm{~mm}$. Tubes were incubated in a shaking water-bath at $37^{\circ} \mathrm{C}$, and transport was stopped after $2 \mathrm{~h}$ with $0.5 \mathrm{ml}$ Trizol reagent (Invitrogen Life Science). Scintillation fluid $(3 \mathrm{ml})$ was added to the vials. Specific radioactivity was determined by liquid scintillation spectrometry. Uptake was expressed as $\mathrm{pmol} /$ islet per $\mathrm{h}$.

\section{D-Glucose utilisation and oxidation}

Glucose utilisation and glucose oxidation were measured in batches of twenty islets in final incubation volumes of $100 \mu \mathrm{l}$ of buffered Krebs-bicarbonate solution supplemented with trace amounts of both $\left[{ }^{5-3} \mathrm{H}\right]$ glucose and $\mathrm{D}-\left[\mathrm{U}-{ }^{14} \mathrm{C}\right]$ glucose $(3 \mu \mathrm{Ci} / \mathrm{ml}$ ) (Amersham Biosciences) as well as non-radioactive glucose at a final concentration of either 2.8 or $8.3 \mathrm{~mm}$. The wells were suspended in $20 \mathrm{ml}$ scintillation vials that were gassed with $95 \% \mathrm{O}_{2}$ and $5 \% \mathrm{CO}_{2}$ and capped airtight with rubber membranes. The vials were then shaken continuously for $2 \mathrm{~h}$ at $37^{\circ} \mathrm{C}$ in a water-bath. After incubation, $0.1 \mathrm{ml}$ of $0 \cdot 2 \mathrm{M}-\mathrm{HCl}$ and $0 \cdot 2 \mathrm{ml} \mathrm{NaCl}$ were injected through the rubber cap into the glass cup containing the incubation medium and into the counting vial, respectively. After $1 \mathrm{~h}$ at $4{ }^{\circ} \mathrm{C}, 10 \mathrm{ml}$ of the scintillation fluid were added to $\mathrm{NaCl}$, and radioactivity was counted. To determine glucose utilisation, cups were transferred to a fresh set of scintillation vials, each containing $500 \mu \mathrm{l}$ of distilled water. The vials containing the islets were then incubated for $18 \mathrm{~h}$ to allow the ${ }^{3} \mathrm{H}$-labelled water in the incubation solution to equilibrate with the water at the base of the vial before the cups and islets were removed, and $10 \mathrm{ml}$ of the scintillation fluid were added to the distilled water. Specific radioactivity was determined by liquid scintillation spectrometry. Rates of glucose utilisation and glucose oxidation were determined and expressed as $\mathrm{pmol} /$ islet per $\mathrm{h}$.

\section{Measurement of intracellular cyclic AMP content}

The cAMP content of islets was determined with the cAMP Enzyme immunoassay system (Amersham cAMP Biotrak Enzyme immunoassay System \#RPN225; Amersham Life Sciences) according to the manufacturer's instructions. Groups of twenty islets were incubated in Krebs solution supplemented with 2.8 or $8.3 \mathrm{~mm}$-glucose in the presence of $250 \mu \mathrm{M}$-IBMX. The content of cAMP was measured by enzyme immunoassay.

\section{Western blotting}

After isolation by collagenase digestion of the pancreas and subsequent separation by handpicking, a pool of at least 500 clean islets from each experimental group was homogenised by sonication $(15 \mathrm{~s})$ in an anti-protease cocktail (10 mM-imidazole at pH 8.0, 4 mm-EDTA, 1 mm-ethylene glycol tetra-acetic acid, $0.5 \mathrm{~g}$ pepstatin $\mathrm{A} / 1,2 \mathrm{~g}$ aprotinin/1, 2.5 mg leupeptin/1, $30 \mathrm{mg}$ trypsin inhibitor/1, $200 \mu \mathrm{M}$-DL-dithiothreitol and $200 \mu \mathrm{M}$-phenylmethylsulfonyl fluoride). After sonication, an aliquot of the extract was collected, and the total protein content was determined by the dye-binding protein assay kit (Bio-Rad Laboratories). Samples containing $50 \mu \mathrm{g}$ of protein from each experimental group were incubated for $5 \mathrm{~min}$ at $80^{\circ} \mathrm{C}$ with $4 \times$ concentrated Laemmli sample buffer ( $1 \mathrm{~mm}$-sodium phosphate at $\mathrm{pH} 7 \cdot 8$, $0 \cdot 1 \%$ bromophenol blue, $50 \%$ glycerol, $10 \%$ SDS and 2\% mercaptoethanol) $(4: 1, \mathrm{v} / \mathrm{v})$ and then run on $10 \%$ polyacrylamide gels at $120 \mathrm{~V}$ for $30 \mathrm{~min}$. Electrotransfer of proteins to nitrocellulose membranes (Bio-Rad) was done for $1 \mathrm{~h}$ at $120 \mathrm{~V}$ (constant) in buffer containing methanol and SDS. After checking the efficiency of transfer by staining with Ponceau $S$, the membranes were blocked with 5\% skimmed milk in TweenTris-buffered saline (TTBS) (10 mm-Tris, $150 \mathrm{~mm}-\mathrm{NaCl}$ and $0.5 \%$ Tween 20 ) overnight at $4^{\circ} \mathrm{C}$. GLUT2, Gck, HxkI, adenylyl cyclase 3 (AC3), PKA $\alpha, \operatorname{PKC} \alpha$ and PLC $\beta 1$ were detected in the membranes after a $2 \mathrm{~h}$ incubation at room temperature with primary antibodies (diluted 1:500, v/v, in TTBS containing 3\% dry skimmed milk; Santa Cruz Biotechnology). The membranes were then incubated with a secondary specific IgG antibody (diluted 1:5000, v/v, in TTBS containing 3\% dry skimmed milk) for $2 \mathrm{~h}$ at room temperature. After incubation with a horseradish peroxidase-conjugated secondary antibody, enhanced chemiluminescence (SuperSignal West Pico) was used for 
detection by autoradiography. Band intensities were quantified by optical densitometry (Scion Image).

\section{Statistical analysis}

The results are presented as means and standard deviations. For the islet data, $n$ refers to the number of experiments performed. To evaluate the effect of PMA or IBMX, values obtained from differences between insulin secretion in the presence and absence of each potentiator were considered. Levene's test for homogeneity of variances was initially used to check the fit of the data to the assumptions for parametric ANOVA. To correct for variance heterogeneity or nonnormality, data were log-transformed ${ }^{(20)}$. Except for the body weight of offspring, which was analysed by one-way ANOVA, and glucose-stimulated insulin secretion, evaluated by threeway ANOVA (nutritional status, physiological status and glucose concentration), all results were analysed by two-way ANOVA (nutritional status and physiological status). Where necessary, these analyses were complemented by the least significant difference test to determine the significance of individual differences. The level of significance was set at $P<0 \cdot 05$. Data were analysed using the Statistica Software package (StatSoft).

\section{Results}

\section{Glucose homeostasis in pregnant rats recovered from early} malnutrition

At the end of the recovery period and before pregnancy, the body weight in the $\mathrm{R}$ groups was significantly lower than in the $\mathrm{C}$ groups, but it was higher than in the LP groups $\left(F_{2,29}=106.5, \quad P<0.0001\right)$. During pregnancy, body-weight gain was higher in the pregnant groups than in the non-pregnant groups, independent of the nutritional status $\left(F_{1,29}=202 \cdot 4\right.$, $P<0.0001)$. However, in pregnant rats, body-weight gain was lower in the LPP group than in the CP group $(P<0.05)$. In the $\mathrm{RP}$ group, body-weight gain did not differ from that of the $\mathrm{CP}$ and LPP groups. Thus, pregnant rats had higher final body weights than non-pregnant rats $\left(F_{1,29}=49 \cdot 2, P<0 \cdot 0001\right)$, but the RP rats exhibited higher final body weights than the LPP rats and lower body weights than the $\mathrm{CP}$ rats $(P<0.05)$. The serum albumin level was lower in the LP groups than in the
$\mathrm{R}$ and $\mathrm{C}$ groups, independent of the physiological status $\left(F_{2,19}=10 \cdot 4, P<0 \cdot 001 ;\right.$ Table 1$)$.

The basal serum glucose levels as well as the mean total areas under the $\Delta G$ curves in response to a glucose load were lower in the pregnant groups than in the non-pregnant groups $\left(F_{1,28}=5 \cdot 2, P<0.03\right.$ and $F_{1,28}=39 \cdot 2, P<0.0001$, respectively), independent of the nutritional status. Pregnancy did not enhance the basal serum insulin concentration in the R group, which had a lower value than the CP and LPP groups $(P<0.05)$. In contrast, the mean total areas under the $\Delta \mathrm{I}$ curves were significantly increased by pregnancy only in the LP diet-fed group. The $\Delta \mathrm{I}$ curve from the RP group was lower than that from the $\mathrm{CP}$ group $(P<0.05)$ and was similar to that of the LPP group. The $\Delta G: \Delta \mathrm{I}$ ratios were significantly affected by nutritional status, physiological status and by the interaction of the two $\left(F_{2,28}=4.4, \quad P<0.05, \quad F_{1,28}=12.1, \quad P<0.001\right.$, $F_{2,28}=4 \cdot 8, P<0 \cdot 05$, respectively). Thus, the $\Delta \mathrm{G}: \Delta \mathrm{I}$ ratio of the LPNP group was higher compared with that of the other groups $(P<0 \cdot 01)$. Pregnancy only reduced the $\Delta \mathrm{G}: \Delta \mathrm{I}$ ratio in the LPP group $(P<0 \cdot 01)$. To measure insulin sensitivity, we performed an insulin tolerance test to calculate glucose disappearance in response to an acute insulin dose. Insulin sensitivity was higher in the LPNP group than in the other groups $\left(F_{2,18}=15 \cdot 3, P<0 \cdot 001\right)$. Moreover, $\mathrm{K}_{\mathrm{itt}}$ in the RNP group was smaller than that in the CNP group $(P<0.05)$. Pregnancy induced insulin resistance in the CP $(P<0.05)$ and LPP $(P<0 \cdot 001)$ groups but not in the RP group, which had $\mathrm{K}_{\mathrm{itt}}$ similar to that in the RNP group (Table 2).

Fetuses from mothers undergoing protein deficiency up to the 12th week of age had lower body weights than those from the other groups $(\mathrm{LPP}=1.5(\mathrm{SD} 0.2) \mathrm{g}, \mathrm{RP}=4.0(\mathrm{SD} 0.4) \mathrm{g}$, $\mathrm{CP}=3.0(\mathrm{SD} 0 \cdot 2) \mathrm{g})$. Recovered rats had $30 \%$ heavier fetuses than those of the $\mathrm{C}$ group $\left(F_{2,30}=187 \cdot 20, P=0 \cdot 000\right)$.

\section{Total insulin content and insulin secretion in islets from pregnant rats recovered from early malnutrition}

Insulin secretion in the presence of $2.8 \mathrm{~mm}$-glucose was greater in islets from the RNP rats than in islets from the LPNP and $\mathrm{CNP}$ rats. In the presence of 8.3 and $16.7 \mathrm{~mm}$-glucose, insulin secretion in islets from the RNP and CNP rats was similar and greater, respectively, compared with the LPNP rats. The dose-response curve for glucose from the LPNP group was shifted to the right compared with the curves from the

Table 1. Initial and final body weight, body-weight gain, serum albumin and total protein concentrations from non-pregnant or pregnant rats maintained on a control diet (CNP and CP, respectively), a low-protein diet (LPNP and LPP, respectively) or recovered after weaning (RNP and RP, respectively) (Number of rats, mean values and standard deviations)

\begin{tabular}{|c|c|c|c|c|c|c|c|c|c|c|c|c|c|c|c|c|c|c|}
\hline \multirow[b]{3}{*}{ Parameters } & \multicolumn{18}{|c|}{ Groups } \\
\hline & \multicolumn{3}{|c|}{ CNP } & \multicolumn{3}{|c|}{$\mathrm{CP}$} & \multicolumn{3}{|c|}{ LPNP } & \multicolumn{3}{|c|}{ LPP } & \multicolumn{3}{|c|}{ RNP } & \multicolumn{3}{|c|}{$\mathrm{RP}$} \\
\hline & $n$ & Mean & SD & $n$ & Mean & SD & $n$ & Mean & SD & $n$ & Mean & SD & $n$ & Mean & SD & $n$ & Mean & SD \\
\hline Initial body weight (g) & 5 & $284^{\mathrm{a}}$ & 23 & 7 & $286^{a}$ & 16 & 6 & $162^{c}$ & 19 & 5 & $162^{\mathrm{c}}$ & 28 & 6 & $222^{\mathrm{b}}$ & 19 & 6 & $218^{b}$ & 14 \\
\hline Final body weight $(\mathrm{g})$ & 5 & $290^{\mathrm{b}}$ & 17 & 7 & $363^{a}$ & 30 & 6 & $174^{d}$ & 28 & 5 & $219^{c}$ & 44 & 6 & $215^{\mathrm{c}}$ & 18 & 6 & $288^{\mathrm{b}}$ & 13 \\
\hline Body-weight gain (g) & 5 & $6^{a, b}$ & 7 & 7 & $76^{c}$ & 19 & 6 & $12^{\mathrm{b}}$ & 10 & 5 & $57^{d}$ & 19 & 6 & $8^{a}$ & 7 & 6 & $71^{\mathrm{c}, \mathrm{d}}$ & 7 \\
\hline Albumin $(g / l)$ & 4 & $29 \cdot 0$ & 0.2 & 5 & $26 \cdot 0$ & 0.4 & 5 & $21 \cdot 0^{*}$ & 0.2 & 4 & $23 \cdot 0^{*}$ & 0.3 & 3 & 28.0 & 0.1 & 4 & $25 \cdot 0$ & 0.2 \\
\hline
\end{tabular}

a,b,c,d Mean values within a row with unlike superscript letters were significantly different $(P<0.05$; least significant difference test)

${ }^{*}$ Mean values were significantly different between nutritional status $(P<0.05$; two-way ANOVA). 
RNP and CNP groups ( $P<0.01$ and $P<0.05$, respectively), and the latter two groups had similar glucose dose-response curves. There was no difference in insulin secretion between the pregnant groups in the presence of $2 \cdot 8$ and $8.3 \mathrm{~mm}$-glucose. In the RP group, maximal insulin release was obtained at a dose of $16.7 \mathrm{~mm}$-glucose, whereas in the LPP and CP groups, maximal insulin secretion occurred at a dose of $11.1 \mathrm{~mm}-$ glucose. Under conditions of 11.1 and $16.7 \mathrm{~mm}$-glucose, insulin secretion in islets from the RP rats was greater compared with that from the LPP and CP rats. In islets from pregnant rats, the dose-response curves were shifted to the left compared with the curves for non-pregnant rats $\left(F_{2,12}=22 \cdot 89\right.$, $P<0.01$ ), except in the RP group, which had a curve similar to that of the RNP group. The half-maximal release concentrations of glucose for islets from the CNP, CP, LPNP, LPP, RNP and RPP groups were $9 \cdot 4$ (SD 1.5), $7 \cdot 7$ (SD 0.15), 11.2 (SD 0.1), $7 \cdot 1(\mathrm{sD} 0 \cdot 5), 8 \cdot 8(\mathrm{sD} 0 \cdot 62)$ and $10 \cdot 4(\mathrm{sD} 0 \cdot 15) \mathrm{mm}$-glucose, respectively (Fig. 1(A)-(C)).

The islets from the LPNP and RNP groups exhibited similar total insulin contents, and these values were significantly lower than those for islets from the CNP group $(P<0.01$ and $P<0.05$, respectively). Pregnancy increased the total insulin content only in the $\mathrm{C}$ and $\mathrm{R}$ groups, but the islets from the $\mathrm{RP}$ group had lower total insulin contents than those from the CP group $(P<0 \cdot 001 ;$ Fig. 1(D)).

At non-stimulatory (Fig. 1(E)) and stimulatory (Fig. 1(F)) glucose concentrations, the increase in insulin secretion induced by IBMX in islets from the LPNP and CNP groups was similar, and this increment was greater than that observed for islets from the RNP group $(P<0 \cdot 0001)$. At a dose of $2.8 \mathrm{~mm}$-glucose, the magnitude of insulin secretion induced by IBMX did not differ among the RP, LPP and CP groups. The potentiator effect of IBMX at a dose of $2.8 \mathrm{~mm}$-glucose was greater in islets from the RP group than those from the RNP group $(P<0 \cdot 001)$, lower in islets from the LPP group than those from the LPNP group $(P<0.01)$ and equal in islets from the $\mathrm{CP}$ and CNP groups. Upon increasing the glucose concentration to $8.3 \mathrm{~mm}$, the magnitude of potentiation of IBMX was greater in islets from all pregnant rat groups compared with those from the non-pregnant rat groups $\left(F_{1,22}=101 \cdot 2, P<0 \cdot 001\right)$.

At a dose of $2.8 \mathrm{~mm}$-glucose, the increase in insulin secretion by PMA was greater in the RNP group than in the LPNP group $(P<0 \cdot 01)$, but the increase in the RNP group was significantly lower compared with that in the CNP group $(P<0 \cdot 001)$. Pregnancy enhanced the potentiator effect of PMA in all groups $\left(F_{1,23}=157 \cdot 4, P<0 \cdot 001\right)$, but this effect was lower in islets from the RP group than in islets from the LPP and CP groups $(P<0 \cdot 001)$, which exhibited a similar magnitude of insulin secretion (Fig. 1(G)). At a dose of $8.3 \mathrm{~mm}$-glucose, the potentiation of insulin secretion by PMA in the islets from the LPNP group was lower than that exhibited by the islets from the CNP group $(P<0 \cdot 05)$. The potentiator effect of PMA in islets from the RNP group did not differ from that exhibited by islets from the LPNP and CNP groups. The magnitude of potentiation of PMA was greater in islets from all pregnant rat groups compared with that in islets from the non-pregnant rat groups $\left(F_{1,19}=92 \cdot 2, \quad P<0 \cdot 001\right)$. However, PMA evoked a similar insulin secretion in islets from the LPP and CP groups, 

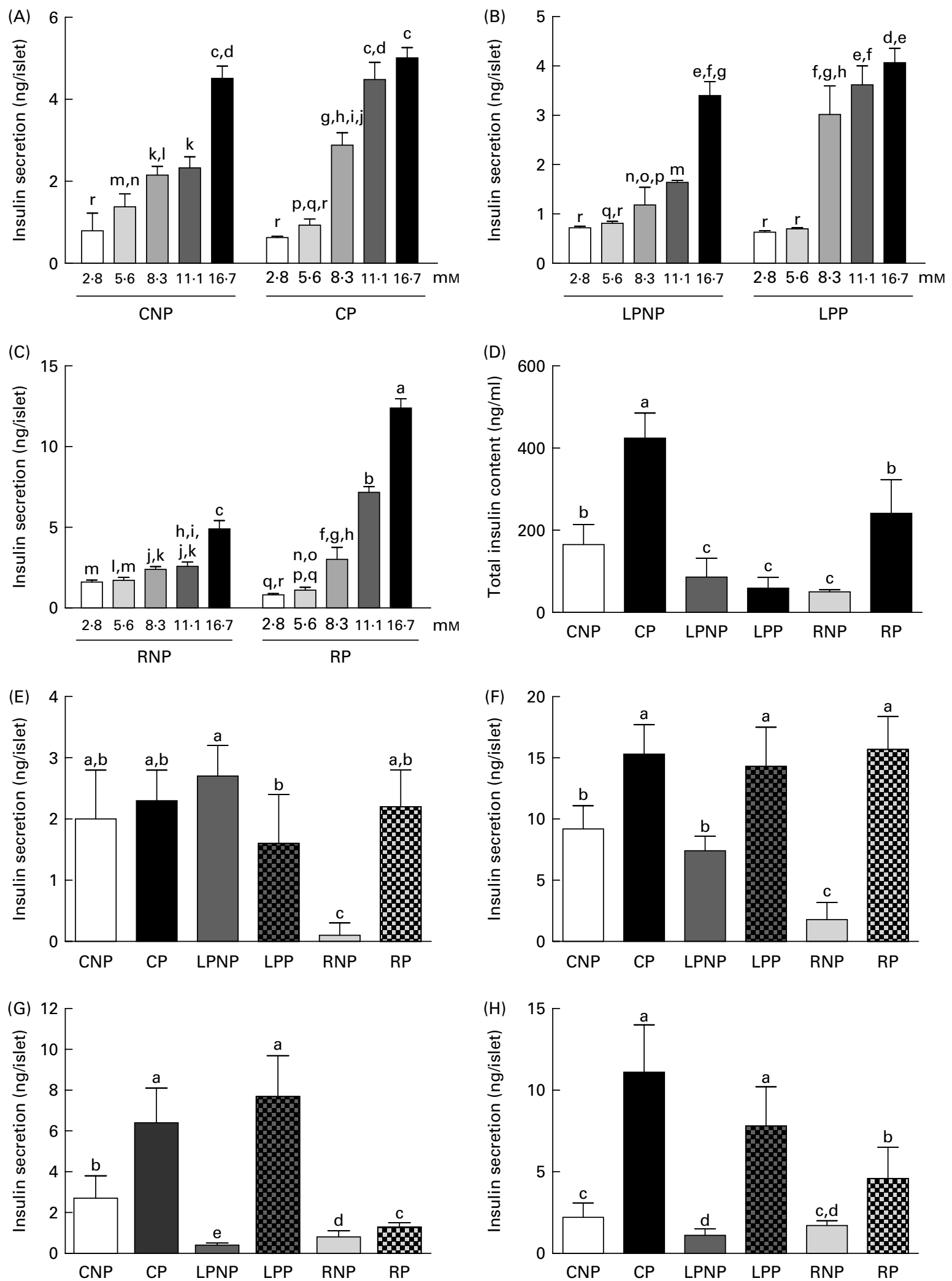

Fig. 1. Glucose stimulation of insulin secretion by islets from the (A) control non-pregnant (CNP) and control pregnant (CP), (B) low-protein non-pregnant (LPNP) and low-protein pregnant (LPP) or (C) recovered non-pregnant (RNP) and recovered pregnant (RP) rats. (D) The total insulin content and the increment in glucose-stimulated insulin secretion ( 2.8 or $8.3 \mathrm{~mm}$-glucose) by (E and $\mathrm{F}$ ) isobutylmethylxanthine and $(\mathrm{G}$ and $\mathrm{H})$ phorbol-2-myristate 13-acetate of islets isolated from the non-pregnant or pregnant rats that had been subjected to the control diet (CNP and CP, respectively) or the low-protein diet (LPNP and LPP, respectively) or those that had recovered after weaning (RNP and RP, respectively). Values are means, with standard deviations represented by vertical bars ( $n 3-8$ experiments). ${ }^{\mathrm{a}-\mathrm{r}}$ Mean values with unlike letters were significantly different $(P<0.05$; least significant difference test). 
and both increases were greater than those exhibited by islets from the RP group $(P<0.05$ and $P<0.01$, respectively; Fig. $1(\mathrm{H})$ ).

\section{Expressions of glucose transporter 2, glucokinase and hexokinase, and glucose metabolism in islets from pregnant rats recovered from early malnutrition}

The GLUT2 content was similar to that in islets from the RNP and LPNP groups, and both groups exhibited a significantly higher GLUT2 content than the CNP $(P<0 \cdot 001)$ and CP groups $(P<0 \cdot 001)$. Pregnancy did not modify the GLUT2 content in islets from the LPP and CP groups in relation to the LPNP and CNP groups, respectively, but it decreased the GLUT2 expression in islets from the RP group compared with those from the RNP group ( $P<0.001$; Fig. 2(A)). The Gck and Hxk contents were affected by nutritional status $\left(F_{2,12}=9 \cdot 9, P<0.05\right.$ and $F_{2,16}=4 \cdot 1, P<0 \cdot 05$, respectively). Thus, islets from the LPP and LPNP groups had higher Gck expression than islets from the RP, RNP, CP and CNP groups (Fig. 2(B)). In contrast, the Hxk expression was lower in islets from the RP and RNP groups compared with those from the other groups (Fig. 2(C)).

The glucose uptake rate observed in the presence of $2.8 \mathrm{~mm}$ glucose was similar in islets from the RNP and CNP groups, and both glucose uptake rates were lower in relation to that exhibited by islets from the LPNP group ( $P<0.001$; Fig. 3(A)). In the presence of $8.3 \mathrm{~mm}$-glucose, islets from the RNP group exhibited a lower glucose uptake rate than islets from the CNP group $(P<0.05)$, a rate which was also lower than that of islets from the LPNP group $(P<0 \cdot 001)$ (Fig. 3(B)). Regardless of the glucose concentration used for the glucose uptake assay, pregnancy increased the glucose uptake rates in islets from the RP $(P<0.001)$ and $\mathrm{CP}$ groups $(P<0.001$ and $P<0.05$, respectively) and reduced the rates in islets from the LPP group $(P<0.001)$ (Fig. 3(A) and (B)).

In the presence of either 2.8 (Fig. $3(\mathrm{C})$ ) or $8.3 \mathrm{~mm}$-glucose, ${ }^{3} \mathrm{H}_{2} \mathrm{O}$ production was similar in all non-pregnant groups (Fig. 3(D)). When $2.8 \mathrm{~mm}$-glucose was used for the assay, pregnancy decreased the glucose utilisation rate in islets from the CP and LPP groups in relation to those from the CNP $(P<0.001)$ and LPNP $(P<0.05)$ groups, respectively, but enhanced it in islets from the RP group compared with those from the RNP group $(P<0 \cdot 001)$ (Fig. 3(C)). After increasing the glucose concentration to $8.3 \mathrm{~mm}$, the glucose utilisation ratio increased in islets from the $\mathrm{CP}$ and $\mathrm{RP}$ groups compared with those from the CNP $(P<0.001)$ and RNP groups $(P<0.05)$, respectively, but not in islets from the LPP group compared with those from the LPNP group (Fig. 3(D)).

To examine the next step in glucose metabolism, we evaluated the glucose oxidation rate in the presence of $2 \cdot 8$ (Fig. 3(E)) and $8.3 \mathrm{~mm}$-glucose (Fig. 3(F)). Under basal conditions, ${ }^{14} \mathrm{CO}_{2}$ production was decreased in islets from the LNP and RNP groups compared with those from the CNP group $(P<0.05)$. Pregnancy improved this parameter in all groups $\left(F_{1,29}=260, P<0 \cdot 001\right)$, but the magnitude of this increment was higher in islets from the LPP group than in those from the CP and RNP groups. Thus, islets from the LPP and CP groups exhibited equivalent oxidation rates, and these rates were higher than those in islets
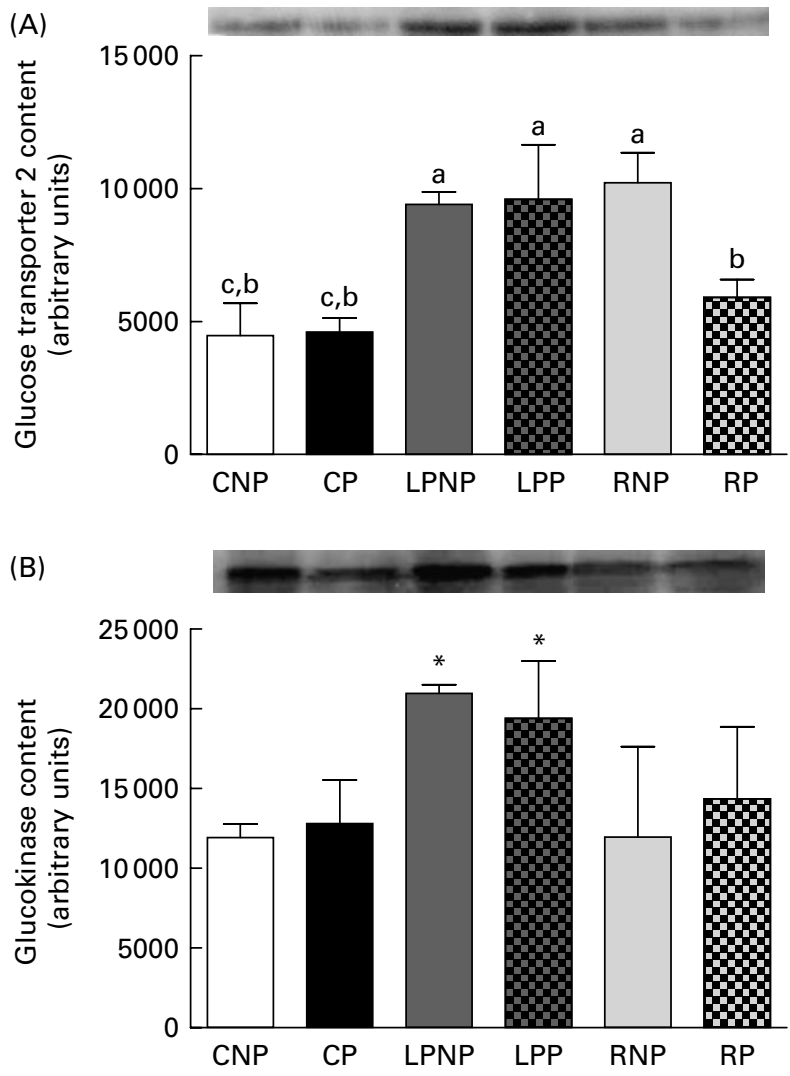

(C)
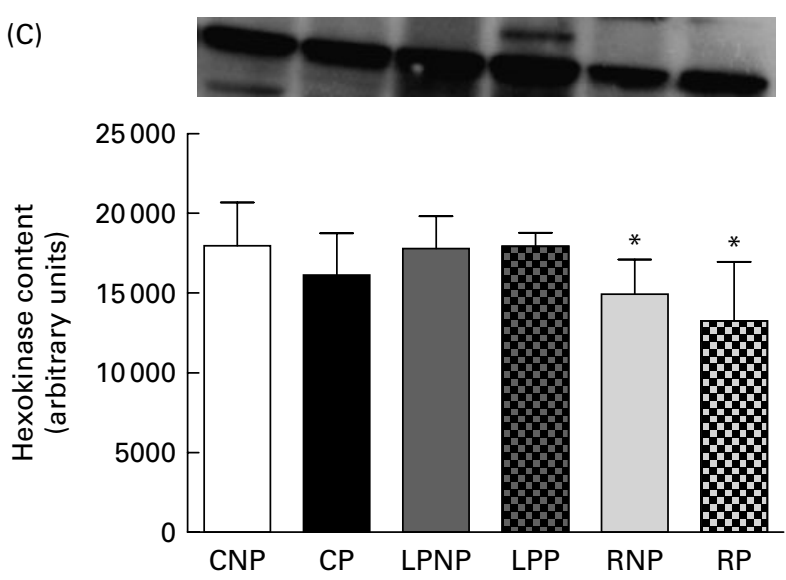

Fig. 2. (A) Glucose transporter 2, (B) glucokinase and (C) hexokinase concentrations detected by Western blot in islets isolated from non-pregnant or pregnant rats maintained on a control diet (CNP and CP, respectively), a low-protein diet (LPNP and LPP, respectively) or recovered after weaning (RNP and RP, respectively). Values are means, with standard deviations represented by vertical bars ( $n$ 3-5 experiments). ${ }^{\text {a,b,c }}$ Mean values with unlike letters were significantly different $(P<0.05$; least significant difference test). * Mean values were significantly different between nutritional status $(P<0.05$; two-way ANOVA).

from the RP group $(P<0 \cdot 05)$. However, the ${ }^{14} \mathrm{CO}_{2}$ production from the latter group was not significantly different from that in the CP group (Fig. 3(E)). Under stimulatory concentrations, the glucose oxidation rate was only altered by physiological status $\left(F_{1,26}=1398 \cdot 0, P<0 \cdot 01\right)$. The islets from pregnant rats had higher glucose oxidation rates compared with the islets from non-pregnant rats (Fig. 3(F)). 

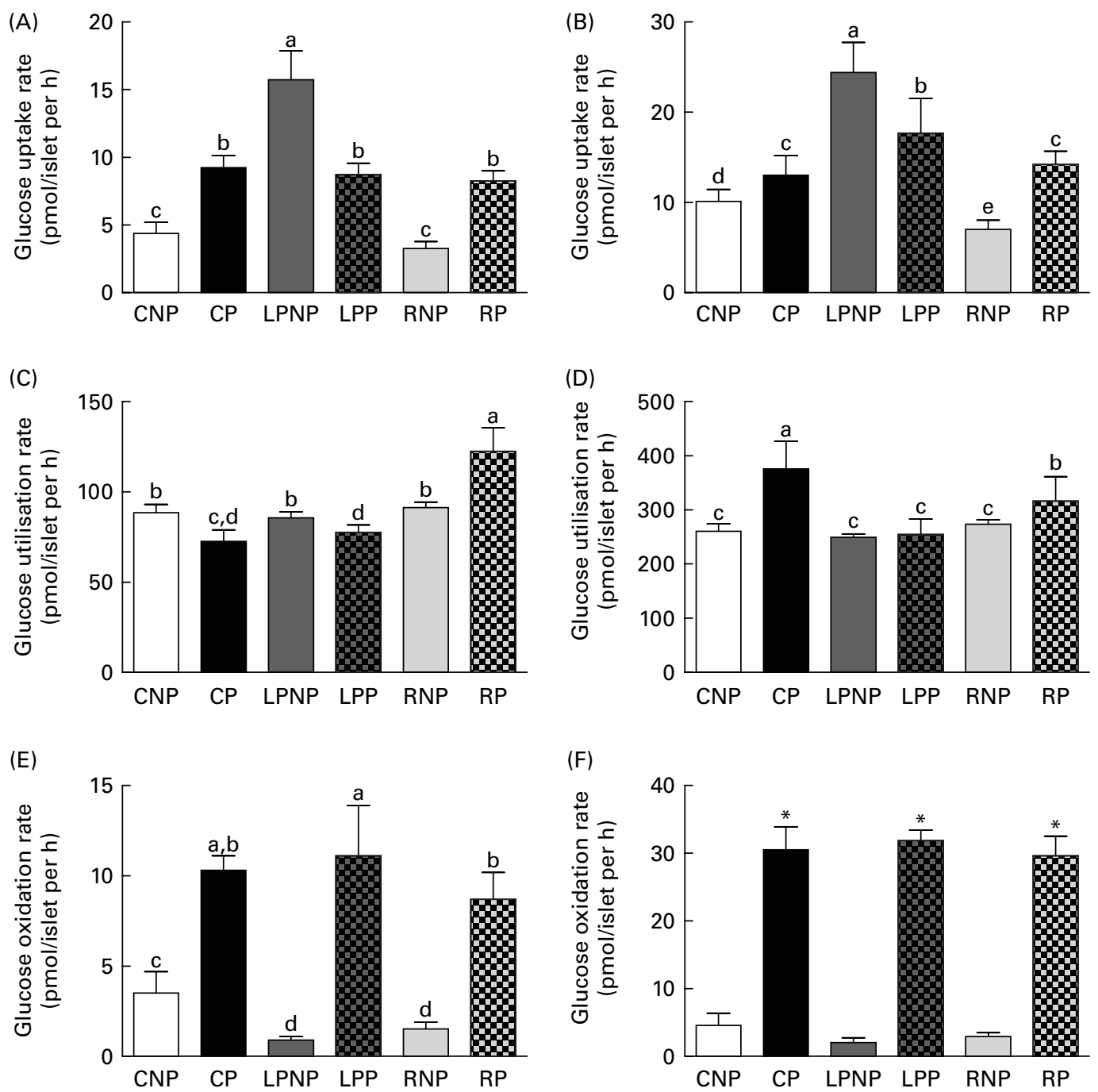

Fig. 3. (A, B) Glucose uptake, (C, D) glucose utilisation and (E, F) glucose oxidation rates in the presence of 2.8 or $8.3 \mathrm{~mm}$-glucose (respectively) in islets isolated from non-pregnant or pregnant rats maintained on a control diet (CNP and CP, respectively), a low-protein diet (LPNP and LPP, respectively) or recovered after weaning (RNP and RP, respectively). Values are means, with standard deviations represented by vertical bars ( $n 8$ experiments). ${ }^{a, b, c, d, e}$ Mean values with unlike letters were significantly different $\left(P<0.05\right.$; least significant difference test). ${ }^{*}$ Mean values were significantly different between physiological status $(P<0.05$; two-way ANOVA).

\section{Intracellular cyclic AMP content in islets from pregnant rats recovered from early malnutrition}

The measurement of intracellular cAMP content was evaluated in the presence of 2.8 or $8.3 \mathrm{~mm}$-glucose with IBMX $(0.5 \mathrm{~mm})$ to inhibit the degradation of this second messenger. In the first condition, the cAMP content was lower in islets from the LPNP group than in those from the RNP and CNP groups $(P<0 \cdot 001)$. Pregnancy increased the intracellular cAMP content in all groups $\left(F_{1,17}=366.5, P<0.001\right)$. However, islets from the RP group had a higher cAMP content than those from the LPP group $(P<0 \cdot 001)$, and islets from the LPP group had a significantly higher cAMP content than those from the CP group $(P<0.001)$ (Fig. 4(A)). In the presence of $8.3 \mathrm{~mm}$-glucose, the intracellular cAMP contents in islets from the RNP and LPNP groups were similar and significantly lower than that in islets from the CNP group $(P<0 \cdot 001)$. Pregnancy enhanced the cAMP content in all groups $\left(F_{1,17}=254 \cdot 7, P<0 \cdot 001\right)$, and no significant difference was observed among the LPP, RP and CP groups (Fig. 4(B))

Expressions of adenylyl cyclase 3, protein kinase A- $\alpha$, phospholipase C- $\beta 1$ and protein kinase $C-\alpha$ in islets from pregnant rats recovered from early malnutrition

The protein content of AC3 in islets from the RNP and LPNP groups was higher than that in islets from the CNP group $(P<0.001)$. Pregnancy increased the AC3 expression by approximately 23 and $124 \%$ in islets from the LPP and CP groups in relation to those from the LPNP $(P<0.01)$ and CNP groups $(P<0.001)$, respectively, and reduced the AC3 expression by approximately $21 \%$ in islets from the RP group compared with those from the RNP group $(P<0 \cdot 01)$ (Fig. 5(A)).

The content of PKA $\alpha$ was modified by nutritional status $\left(F_{2,12}=16 \cdot 60 ; P<0.001\right)$. Thus, the islets from the R (RNP and RP) and LP (LPNP and LPP) rats had PKA $\alpha$ contents that were 

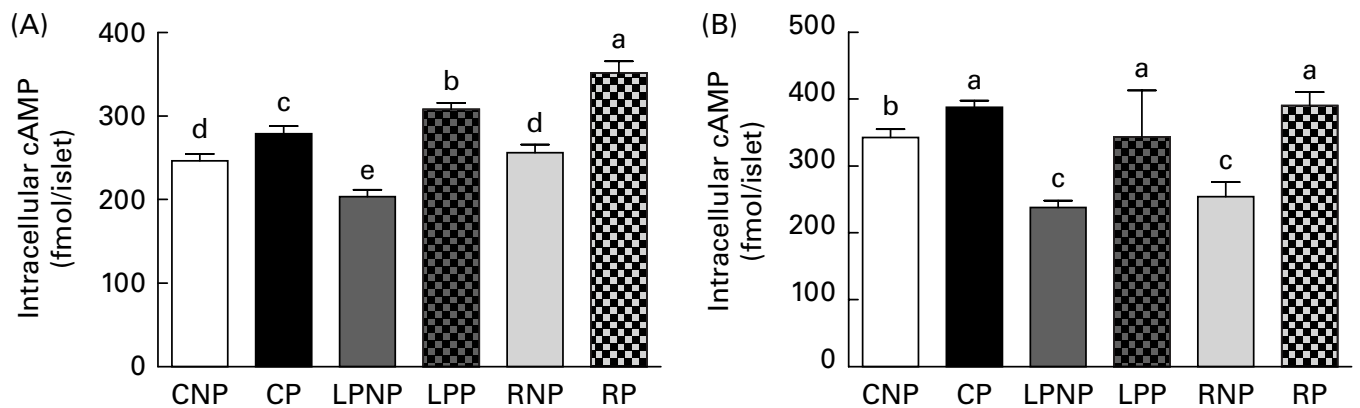

Fig. 4. Intracellular cyclic AMP (cAMP) content in the presence of (A) 2.8 or (B) $8.3 \mathrm{~mm}$-glucose in islets isolated from non-pregnant or pregnant rats subjected to a control diet (CNP and CP, respectively), a low-protein diet (LPNP and LPP, respectively) or recovered after weaning (RNP and RP, respectively). Values are means, with standard deviations represented by vertical bars ( $n 10$ experiments). ${ }^{a, b, c, d, e}$ Mean values with unlike letters were significantly different $(P<0.05$; least significant difference test).

156 and $118 \%$ higher than the islets from the $\mathrm{C}$ rats (CNP and CP), respectively (Fig. 5(B)).

The PLC $\beta 1$ content was higher in islets from the RNP and LPNP groups than that in islets from the CNP group $(P<0.01$ and $P<0 \cdot 05$, respectively). The islets from the LPP and CP groups had higher PLC $\beta 1$ protein expression than those from the LPNP $(P<0.05)$ and CNP groups $(P<0 \cdot 001)$, respectively, whereas the islets from the RP group exhibited similar PLC $\beta 1$ protein expression levels to those from the RNP group. The PLC $\beta 1$ protein expression did not differ among the three pregnant groups (Fig. 5(C)). The protein expression of PKC $\alpha$ in islets from the RP rats was lower than that in islets from the RNP group
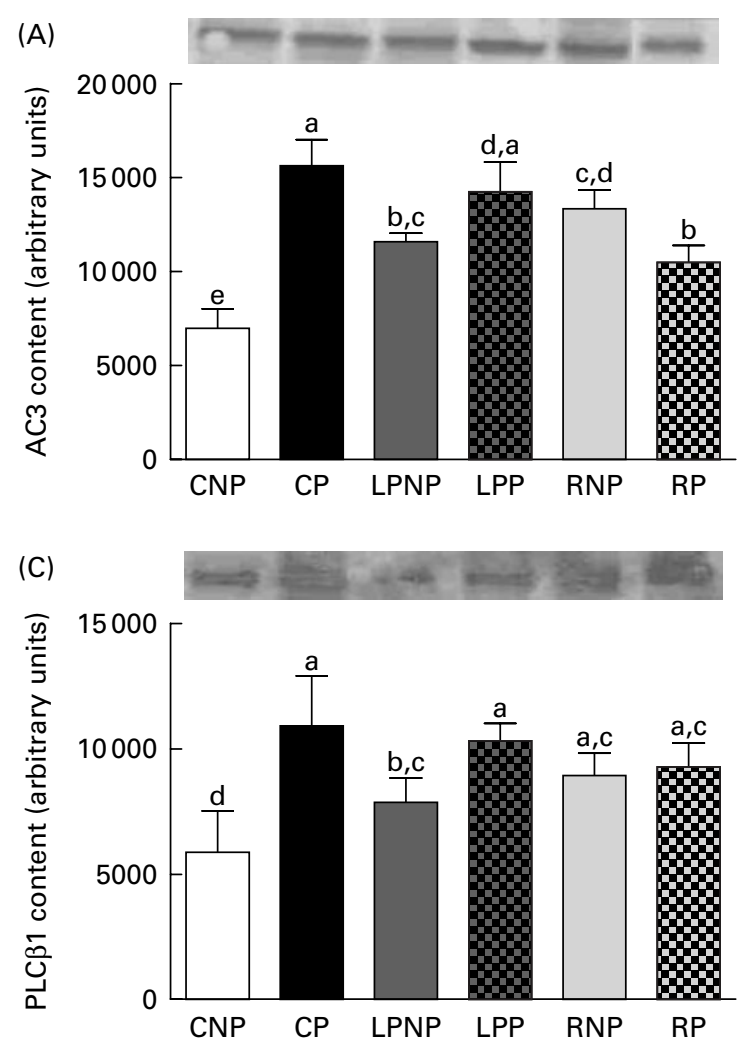

$(P<0 \cdot 01)$, whereas its content was similar in islets from the $\mathrm{CP}$, LPP, CNP and LPNP groups (Fig. 5(D)).

\section{Discussion}

In the present study, recovered non-pregnant rats demonstrated the indicators of in vivo (fasting serum insulin concentration, $\Delta \mathrm{I}$ and $\Delta \mathrm{G}: \Delta \mathrm{I}$ ratio) and in vitro (doseresponse curve) insulin secretions similar to control nonpregnant rats, despite a deficit in the total insulin content per islet in relation to the control non-pregnant rats. Furthermore, recovered non-pregnant rats were more insulin resistant
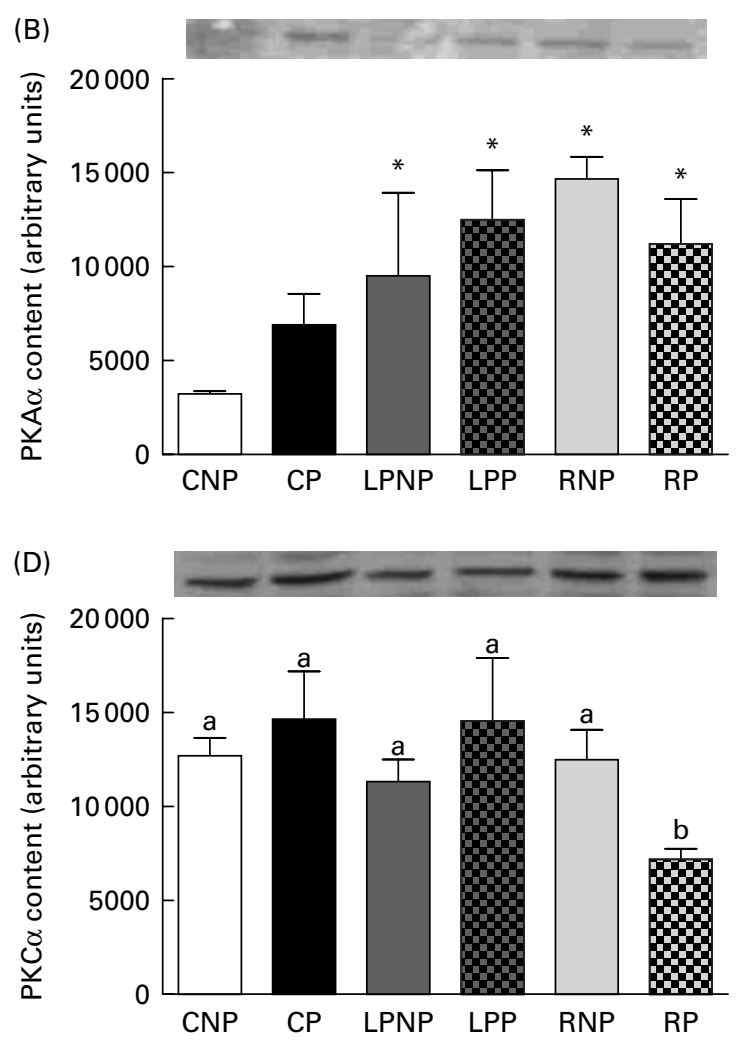

Fig. 5. (A) Adenylyl cyclase 3 (AC3), (B) protein kinase A- $\alpha$ (PKA $\alpha)$, (C) phospholipase C- $\beta 1$ (PLC $\beta 1)$ and (D) protein kinase C- $\alpha$ (PKC $\alpha)$ concentrations detected by Western blot in islets isolated from non-pregnant or pregnant rats maintained on a control diet (CNP and CP, respectively), a low-protein diet (LPNP and LPP, respectively) or recovered after weaning (RNP and RP, respectively). Values are means, with standard deviations represented by vertical bars ( $n 3-4$ experiments). ${ }^{\text {a,b,c,d,e }}$ Mean values with unlike letters were significantly different $\left(P<0 \cdot 05\right.$; least significant difference test). ${ }^{\star}$ Mean values were significantly different between nutritional status $(P<0.05$; two-way ANOVA). 
than low-protein and control non-pregnant rats, but their glucose tolerance (accessed by $\Delta \mathrm{G}$ and fasting glucose concentration) was similar to the glucose tolerance of those two groups. In a previous study ${ }^{(9)}$, male low-protein and recovered rats exhibited increased insulin sensitivity, normal total insulin content per islet and impairment of insulin secretion. Differences between sexes may be related to a diverse hormonal milieu that could be modulating insulin secretion and sensitivity. The present results are contrary to the observation that females fed a low-protein diet during early life become relatively more insulin deficient and glucose intolerant $^{(21)}$. However, alterations in the metabolic pathway that contribute to glucose intolerance may be related to the age of the animals studied. For example, Chamson-Reig et $a l .{ }^{(21)}$ observed animals at $130 \mathrm{~d}$ of age, whereas the present study was conducted with animals that were $90 \mathrm{~d}$ old.

Islets from female rats fed a low-protein diet up to the 12th week of age displayed greater glucose uptake but similar glucose utilisation compared with islets from the control rats. Thus, we hypothesised that glucose that is not metabolised by glycolysis is shifted to other pathways, such as the pentosephosphate shunt, providing $\beta$-cells with either NADP as a high-energy substrate for insulin secretion or ribose substrates for the synthesis of nucleotides. Interestingly, the expression of Gck and Hxk did not correlate with the glucose utilisation rate and was not consistent with insulin secretory profiles observed in islets from low-protein and recovered non-pregnant rats. These results suggest that Gck and Hxk activity is more important than Gck and Hxk expression for determining the glycolytic flux and the shift of the dose-response curve. This supposition is reinforced by a report that islets from rats recovered from early malnutrition after weaning displayed reduced Gck and Hxk activity ${ }^{(3)}$. Finally, in contrast to evidence suggesting that GLUT2 may be an essential enabling factor for glucose responsiveness ${ }^{(22)}$, in the present study, islets from the low-protein and recovered non-pregnant rat groups that overexpressed GLUT2 exhibited different glucose responsiveness.

The ability of cAMP to potentiate insulin secretion stimulated by glucose through the activation of PKA is well documented $^{(23)}$. In the present study, islets from the low-protein and recovered non-pregnant rats exhibited reduced cAMP content despite increased AC3 content. Because cAMP generation dependent on the AC3 isoform is modulated by $\mathrm{Ca}^{2+} /$ calmodulin complexes ${ }^{(24)}$, and $\mathrm{Ca}^{2+}$ handling is compromised in islets from low-protein non-pregnant rats $^{(4)}$, it is reasonable to speculate that AC activity was reduced, at least in islets from low-protein non-pregnant rats. The lower potentialisation magnitude elicited by IBMX on insulin secretion in the face of increased PKA expression observed in islets from the lowprotein and recovered non-pregnant rats also indicates impaired PKA activity, but to a greater degree in islets from the recovered non-pregnant rats than from the low-protein non-pregnant rats.

The PLC/PKC pathway was also altered in islets from the recovered and low-protein non-pregnant rats. The PLC content was increased in both groups, possibly in an attempt to increase inositol 1,4,5-triphosphate and diacylglycerol levels. The PKC content was not modified, but its activity was reduced, especially in islets from the low-protein non-pregnant rats, considering the weak PMA potentialisation on insulin secretion.

Curiously, the pattern of insulin resistance ${ }^{(13,25)}$ and the functional changes of the endocrine pancreas ${ }^{(8)}$ typical of pregnancy were observed in the low-protein pregnant rats but not in the recovered pregnant rats. Even so, recovered pregnant rats did not develop gestational diabetes or glucose intolerance, possibly because insulin sensitivity and insulin secretion were reciprocally related. However, fetuses from the recovered pregnant rats exhibited greater body weights than those from the low-protein and control pregnant rats, which is an indication of disrupted maternal metabolism.

To address the increased insulin demand, islets should combine mechanisms that enhance their secretory capacity and reduce the threshold for glucose-stimulated insulin secretion. Total insulin content per islet, a measure that reflects insulin biosynthesis and/or $\beta$-cell mass, must be amplified during pregnancy ${ }^{(8)}$. In the present study, islets from the recovered pregnant rats increased the total insulin content, but it was not enough to reach the value of islets from the control pregnant rat group. However, islets from the recovered pregnant rats exhibited greater glucose responsiveness and lower glucose sensitivity than islets from the control rats. In contrast, islets from the low-protein pregnant rats had lower total insulin content and reduced glucose responsiveness but similar glucose sensitivity in relation to islets from the control pregnant rats. These results suggest alterations in one or more mechanisms of insulin secretion.

The glucose-stimulated insulin response curves shifted to lower glucose concentrations during pregnancy, has been associated with an increase in glucose utilisation due to the enhanced activity and/or content of GLUT2, Gck and Hxk, as well as to an increase in glucose oxidation ${ }^{(9)}$. Contrary to these assumptions, the Gck and Hxk contents in the present study were not altered in any pregnant groups, but the doseresponse curve for islets from the recovered pregnant rats was shifted to the right in relation to islets from the low-protein and control pregnant rats. The GLUT2 content and glucose uptakes were similar across the islets from the recovered and control pregnant rats. Thus, there are no correlations between GLUT2, Gck and Hxk expression and glucose sensitivity in islets from the pregnant rats. In addition, islets from the control pregnant rats did not show enhancement of GLUT2, Gck or Hxk contents, but exhibited glucose uptake, utilisation and oxidation compatible with increased glucose sensitivity. It is interesting to emphasise that Weinhaus et al. ${ }^{(9)}$ observed similar Gck and Hxk expression levels in control islets and islets at day 15 of pregnancy on a protein equivalence basis. Increased Gck and Hxk expressions were observed only when enzyme levels were normalised on the basis of DNA. Considering that our glucose utilisation and oxidation results in islets from the recovered and low-protein rats did not correlate with the changes observed in glucose sensitivity, we investigated other pathways of stimulus-secretion coupling that could explain the secretory pattern exhibited by islets from the low-protein and recovered rats

The expected rise in cAMP generation previously reported in pregnancy ${ }^{(11)}$ was observed in the present study, even in islets 
from the recovered pregnant rats with decreased AC3 contents. The cAMP generation profile of islets from the recovered and low-protein pregnant rats indicated increased AC3 activity. As previously reported ${ }^{(12)}$, pregnancy did not increase the PKA content. However, taking into account the increased cAMP generation and the potentiator effect of IBMX in low glucose concentrations, it is possible to infer that PKA activity was reduced in islets from the pregnant rats subjected to prolonged protein restriction, as well as in islets from the pregnant rats rescued from early protein restriction. Hence, the pattern of glucose sensitivity observed in islets from the recovered and low-protein pregnant rats did not correlate with alterations in the cAMP/PKA pathway.

The PLC/PKC system is involved in the reduction of the stimulatory threshold glucose concentration and in the potentiation of insulin secretion during pregnancy ${ }^{(8)}$, and this system is impaired in a model of protein restriction after weaning ${ }^{(26)}$. The PLC content was similar across all islets from the pregnant rats, and PKC expression was reduced in islets from the recovered pregnant rats. In addition, PMA was less efficient in potentiating insulin secretion in the recovered pregnant rats, indicating a lower PKC activity in that group. Thus, the PLC/PKC system in islets from the recovered pregnant rats appears to be severely attenuated.

\section{Conclusion}

These results suggest that protein restriction in early life impairs the classical $\beta$-cell adaptive changes during pregnancy and disrupts maternal metabolism, but not enough to promote the onset of gestational diabetes. The loss of the adaptive capacity of islets from the recovered pregnant rats apparently resulted from the uncoupling of glucose metabolism and the amplifying signals of the secretory process, as well as from a severe attenuation of the PLC/PKC pathway. Alterations exhibited by islets from the pregnant rats undergoing sustained protein deficiency up to the 12th week of age appeared to result more from reduced islet mass and/or insulin biosynthesis than from impairment of the stimulussecretion coupling process.

\section{Acknowledgements}

The authors are grateful to Celso Roberto Afonso for excellent technical assistance and to Dr Maria Alice Rostom de Mello for kindly providing the $\left[{ }^{14} \mathrm{C}\right] 2$-deoxy-D-glucose for glucose metabolism assays in isolated islets. This study was supported by the Brazilian foundations $\mathrm{CNPq}$ (Conselho Nacional de Desenvolvimento Científico e Tecnológico, grant no.: 305155/ 2004-0), FAPEMAT (Fundação de Amparo à Pesquisa do Estado de Mato Grosso, grant no.: 0786/2006) and CAPES (Coordenação de Aperfeiçoamento de Pessoal de Nível Superior, grant no.: PROCAD 022/2007). This work is part of a dissertation presented by Letícia Martins Ignácio de Souza as a partial requirement for the Master's degree in Biosciences at the Faculty of Nutrition, Universidade Federal de Mato Grosso. L. M. I.-S. and S. R. R. carried out the assays in isolated islets, B. L. B. conducted the in vivo experiments. V. C. A.,
R. V. V. and F. F. performed the RIA and analysis and interpretation of the data. A. C. B., E. M. C. and M. A. d. B. R. contributed equally to this work in various aspects of this study. M. Q. L. conceived and designed the study. L. M. I.-S. drafted the manuscript along with the other authors. All authors read and approved the final manuscript. The authors declare that they have no conflict of interest.

\section{References}

1. Oliveira CA, Latorraca MQ, de Mello MA, et al. (2011) Mechanisms of insulin secretion in malnutrition: modulation by amino acids in rodent models. Amino Acids $\mathbf{4 0}$, 1027-1034.

2. Latorraca MQ, Reis MA, Carneiro EM, et al. (1998) Protein deficiency and nutritional recovery modulate insulin secretion and the early steps of insulin action in rats. $J$ Nutr 128, 1643-1649.

3. Heywood WE, Mian N, Milla PJ, et al. (2004) Programming of defective rat pancreatic beta-cell function in offspring from mothers fed a low-protein diet during gestation and the suckling periods. Clin Sci 107, 37-45.

4. Latorraca MQ, Carneiro EM, Mello MA, et al. (1999) Reduced insulin secretion in response to nutrients in islets from malnourished young rats is associated with a diminished calcium uptake. J Nutr Biochem 10, 37-43.

5. Cherif H, Reusens B, Dahri S, et al. (2001) A proteinrestricted diet during pregnancy alters in vitro insulin secretion from islets of fetal Wistar rats. J Nutr 131, 1555-1559.

6. Parsons JA, Brelje TC \& Sorenson RL (1992) Adaptation of islets to pregnancy: increase in B-cell division and insulin secretion correlates with onset of placental lactogen secretion. Endocrinology 130, 1459-1466.

7. Green IC \& Taylor KW (1972) Effects of pregnancy in the rat on size and insulin secretory response of islets of Langerhans. J Endocrinol 54, 317-325.

8. Sorenson RL \& Brelje TC (1997) Adaptation of islets of Langerhans to pregnancy: beta-cell growth, enhanced insulin secretion and the role of lactogenic hormones. Horm Metab Res 29, 301-307.

9. Weinhaus AJ, Stout LE \& Sorenson RL (1996) Glucokinase, hexokinase, glucose transporter 2, and glucose metabolism in islets during pregnancy and prolactin-treated islets in vitro: mechanisms for long term up-regulation of islets. Endocrinology 137, 1640-1649.

10. Weinhaus AJ, Stout LE, Bhagroo NV, et al. (2007) Regulation of glucokinase in pancreatic islets by prolactin: a mechanism for increasing glucose-stimulated insulin secretion during pregnancy. J Endocrinol 193, 367-381.

11. Weinhaus AJ, Bhagroo NV, Brelje TC, et al. (1998) Role of CAMP in upregulation of insulin secretion during the adaptation of islets of Langerhans to pregnancy. Diabetes $\mathbf{4 7}$, 1426-1435.

12. Milanski M, Arantes VC, Ferreira F, et al. (2005) Low-protein diets reduce PKAalpha expression in islets from pregnant rats. J Nutr 135, 1873-1878.

13. Leturque A, Ferré $\mathrm{P}$, Sabatin $\mathrm{P}$, et al. (1980) In vivo insulin resistance during pregnancy in the rat. Diabetologia $\mathbf{1 9}$, $521-528$.

14. Matthews JN, Altman DG, Campbell MJ, et al. (1990) Analysis of serial measurements in medical research. BMJ 300, $230-235$. 
15. Lundbaek K (1962) Intravenous glucose tolerance as a tool in definition and diagnosis of diabetes mellitus. $\mathrm{Br}$ Med J 5291, 1507-1513.

16. Trinder P (1969) Determination of blood glucose using an oxidase-peroxidase system with a non-carcinogenic chromogen. J Clin Pathol 22, 158-161.

17. Doumas BT, Watson WA \& Biggs HG (1971) Albumin standards measurements of serum albumin with bromocresol green. Clin Chim Acta 31, 87-96.

18. Scott AM, Atwater I \& Rojas E (1981) A method for the simultaneous measurement of insulin release and $\beta$-cell membrane potential in single mouse islets of Langerhans. Diabetologia 21, 470-475.

19. Boschero AC, Szpak-Glasman N, Carneiro EM, et al. (1995) Oxotremorine-m potentiation of glucose-induced insulin release from rat islets involves M3 muscarinic receptors. Am J Physiol 268, E336-E342.

20. Sokal RR \& Rohlf FJ (1995) Biometry: The Principles and Practice of Statistics in Biological Research, 3rd ed. New York, NY: W.H. Freeman and Company.

21. Chamson-Reig A, Thyssen SM, Hill DJ, et al. (2009) Exposure of the pregnant rat to low protein diet causes impaired glucose homeostasis in the young adult offspring by different mechanisms in males and females. Exp Biol Med 234, 1425-1436.

22. Johnson JH \& Newgard CB (1996) The role of glucose transport and phosphorylation in glucose-stimulated insulin secretion. In Diabetes Mellitus, 1st ed., pp. 42-48 [D LeRoith, SI Taylor and JM Olefsky, editors]. Philadelphia: LippincotRaven.

23. Yang Y \& Gillis (2004) A highly $\mathrm{Ca}^{2+}$-sensitive pool of granules is regulated by glucose and protein kinases in insulin-secreting INS-1. J Gen Physiol 124, 641-651.

24. Tian Y \& Laychock SG (2001) Protein kinase C and calcium regulation of adenylyl cyclase in isolated rat pancreatic islets. Diabetes 50, 2505-2513

25. Freemark M (2006) Regulation of maternal metabolism by pituitary and placental hormones: roles in fetal development and metabolic programming. Horm Res 65, 41-49.

26. Ferreira F, Barbosa HC, Stoppiglia LF, et al. (2004) Decreased insulin secretion in islets from rats fed a low protein diet is associated with a reduced PKAalpha expression. $J$ Nutr 134, 63-67. 